\title{
Quantitative study of irradiation damage in organo-metallic colloïdal particles
}

\author{
J. Wery and J.L. Mansot \\ Laboratoire de Physique Cristalline, Institut des Matériaux de Nantes, 2 rue de la Houssinière, 44072 \\ Nantes cedex 03, France
}

(Received 5 April 1993, accepted 28 May 1993)

\begin{abstract}
Résumé. - Une étude des dégâts d'irradiation subis par des particules colloidales d'isooctanoate de plomb est réalisée au moyen de la diffraction électronique et de la spectroscopie de pertes d'énergie d'électrons transmis résolues dans le temps. L'étude porte à la fois sur les transformations structurales et chimiques provoquées par le faisceau d'électrons. Les résultats sont interprétés en utilisant une approche de type cinétique chimique qui nous permet de déduire les ordres partiels de réaction relatifs à la concentration d'isooctanoate de plomb et au taux d'irradiation.
\end{abstract}

\begin{abstract}
Irradiation damage in colloidal particles of lead isooctanoate are investigated by means of time resolved low dose Electron Diffraction and Electron Energy Loss Spectroscopy. Both structural and chemical transformations are studied. The kinetic of the irradiation damage process is interpreted using a chemical type approach which allows us to deduce the partial orders relative to the lead isooctanoate concentration and electron dose rate.
\end{abstract}

\section{Introduction.}

When a specimen is studied by means of transmission electron microscopy, it can undergo some irradiation damage leading to structural disorder and/or loss of chemical species. Many studies have been carried out on metal oxides [1-4], mineral halides [5-7] or organic materials [8-11]. The authors point out the role of some parameters especially: the accelerating voltage, the electron dose, the temperature of the specimen, its structure and thickness.

In this paper we are concerned with the quantification of irradiation damage in a "composite material" composed of colloïdal particles of lead isooctanoate. This study is carried out at three levels, structural changes, molecular and elemental evolution, in order to deduce a kinetic equation and to propose an irradiation damage mechanism. 


\section{Products.}

The product studied is a non-stoichiometric lead 3.5 dimethyl hexanoate (called lead isooctanoate in the paper and symbolized by PbIso to simplify the mathematical expressions). This compound is obtained through a polyphasic reaction in non polar solvent (white spirit) between 3.5 dimethyl hexanoic acid and lead oxide $(\mathrm{PbO})$ in the litharge phase [12]. Its formula is: $(\mathrm{RCOO})_{2} \mathrm{~Pb}$, $(\mathrm{PbO})_{0.5}$. The structure of the reverse micelles obtained has been described in previous papers $[12,13]$ and can be assimilated to small fraction of Langmuir film dispersed in the solvent; each micellar particle has a size in the range $10-15 \AA$.

For this irradiation study, the specimen is prepared by the langmuir trough method well described elsewhere $[14,15]$. One drop of the dispersion is deposited onto the free surface of distilled water and the thin surface film (thickness lower than $10 \mathrm{~nm}$ ) so obtained is immediatly deposited onto a holey carbon grid. For electron diffraction studies, one drop of the dispersion is directly deposited onto the carbon grid.

\section{Experimental conditions.}

The studies have been carried out on a CM30 Philips microscope running at $200 \mathrm{kV}$ with an LaB6 cathode. Low dose diffraction patterns were dynamically recorded using a low light level camera. The quantification of the Debye-Scherrer rings intensity is done in hybrid diffraction mode.

Electron Energy Loss Spectroscopy (EELS) experiments were performed using a Gatan spectrometer with parallel detection [16]. The spectra were recorded in the diffraction coupling mode using a condenser aperture of $100 \mu \mathrm{m}$ diameter (convergence half angle $=0.3 \mathrm{mrad}$ ), an objective aperture of $50 \mu \mathrm{m}$ diameter (collection half angle $=8.3 \mathrm{mrad}$ ) and a spectrometer entry aperture of $2 \mathrm{~mm}$ leading to a resolution of $1.0 \mathrm{eV}$ (FWHM of the zero loss peak).

\section{Results.}

A typical micrograph of the colloïdal particles is presented in figure 1a. They appear as circular dark areas with typical sizes in the range 40-80 $\AA$ (Fig. 1d). These particles greater than the micelles, are due to the coalescence of the micelles during the preparation process (schematic representation in Fig. 1e [12]). The thickness of these aggregates is in the range 10-20 $\AA$. The low dose diffraction pattern recorded by means of the camera (Fig. 1b) presents only two enlarged Debye-Scherrer rings due to the nanocrystalline structure of the particles. The EELS low dose spectrum shows the presence of carbon, lead and oxygen in these particles. The near edge structures of the carbon $\mathrm{K}$ edge reveal the presence of $\mathrm{C}-\mathrm{C}, \mathrm{C}-\mathrm{H}, \mathrm{C}-\mathrm{O}$ and $\mathrm{C}=\mathrm{O}$ bonding (Fig. 1c).

4.1 Structural EVOLUTION. - Typical low dose diffraction patterns are presented in figure 2 at the beginning of the examination and after various irradiation doses for a constant experimental dose rate of $2 \mathrm{e} / \AA^{2} \mathrm{~s}$ (measured by means of the EEL spectrometer). In these conditions the overheating of the sample is estimated at about $10 \mathrm{~K}$ [17] and consequently can be neglected. At the beginning of the examination only two enlarged Debye-Scherrer rings corresponding to interreticular distances of 4.95 and $3.32 \AA$, due to short range order in the particles, are clearly visible. During the irradiation process, they progressively disappear and are replaced by five well defined rings corresponding to interreticular distances of $2.855 \AA$ (111), $2.475 \AA(200), 1.750 \AA$ (320), $1.483 \AA$ (311) and $1.429 \AA$ (222). This last diffraction pattern can be indexed into f.c.c. lead 

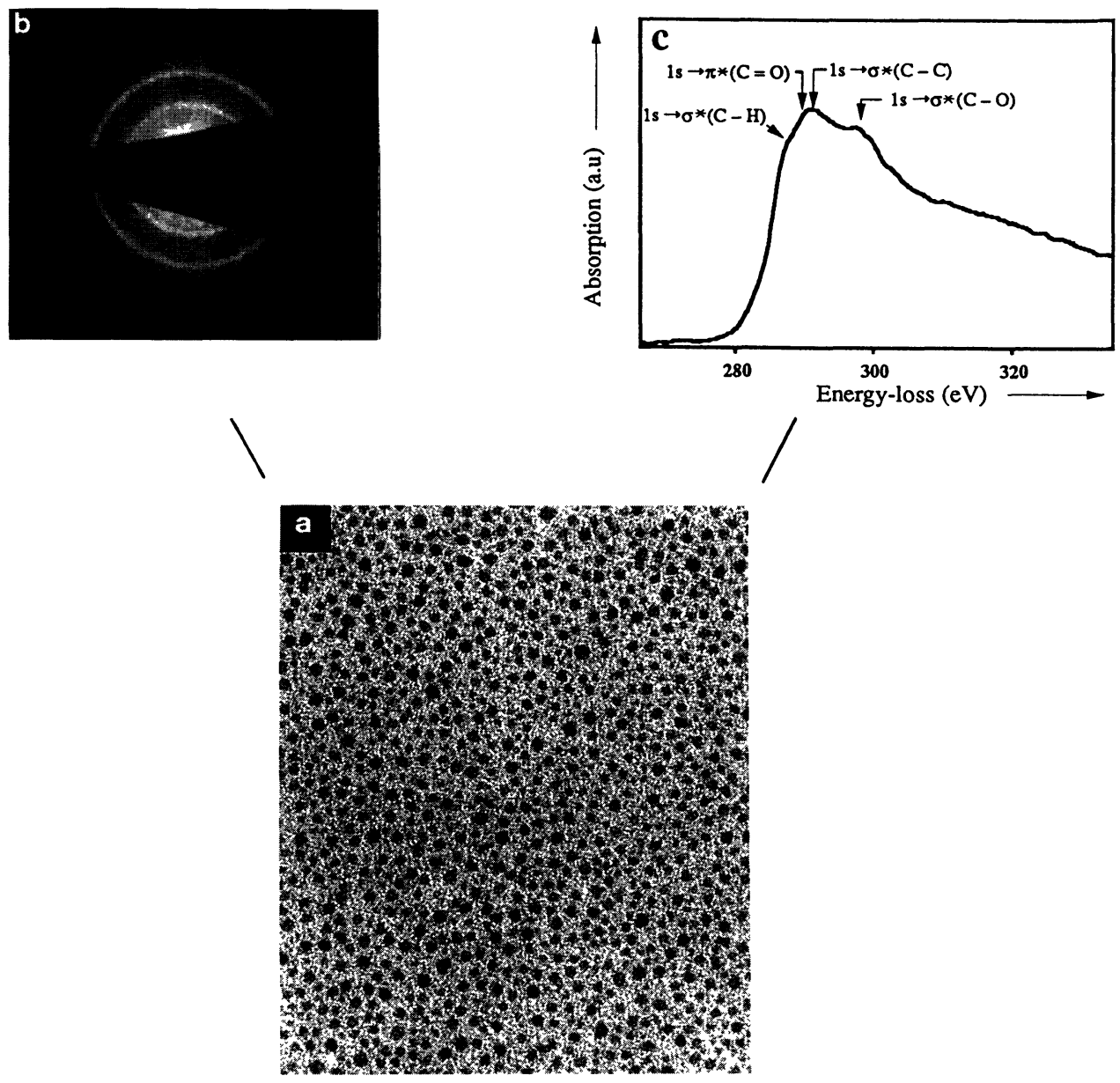

$-27 \mathrm{~mm}$
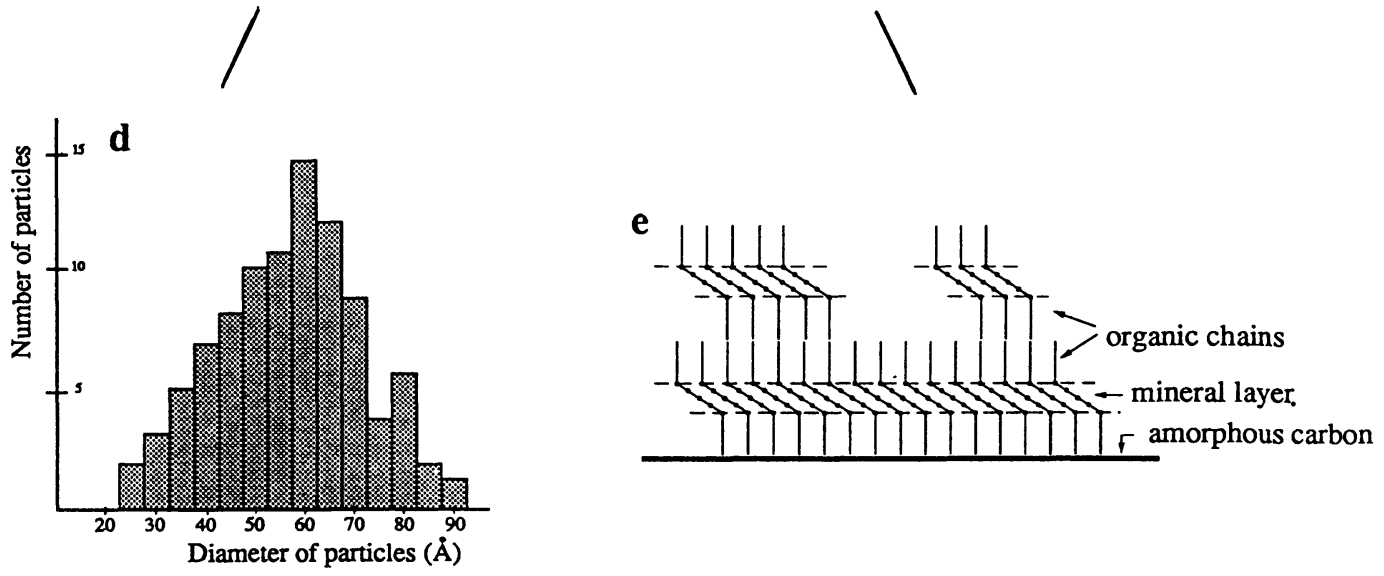

Fig. 1. - a) Low magnification transmission electron micrograph in bright field imaging mode. b) Low dose electron diffraction pattern obtained at the beginning of examination. c) Low dose Electron Energy Loss Spectrum of the particles. d) Size distribution of the lead isooctanoate colloïdal particles. e) Schematic representation of the particles. 


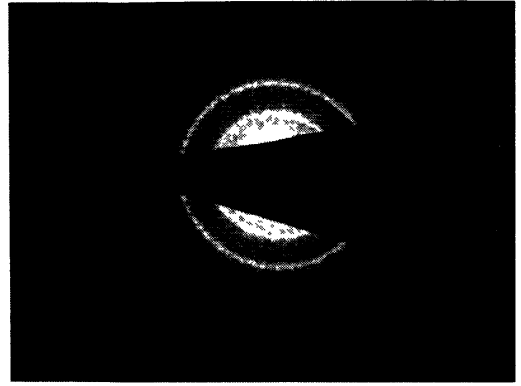

$\mathrm{t}=\mathbf{0} \mathrm{s}$ (zero dose)

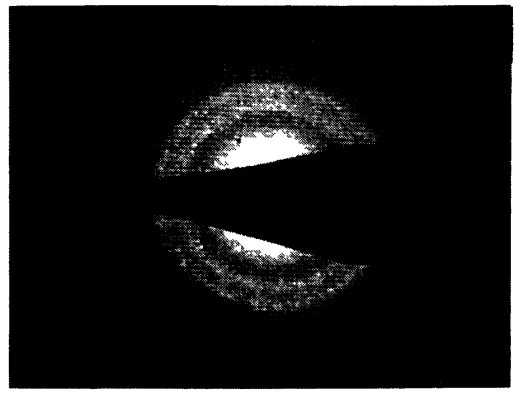

$\mathrm{t}=25 \mathrm{~s}\left(\right.$ dose $\left.=50 \mathrm{e} / \AA^{2}\right)$

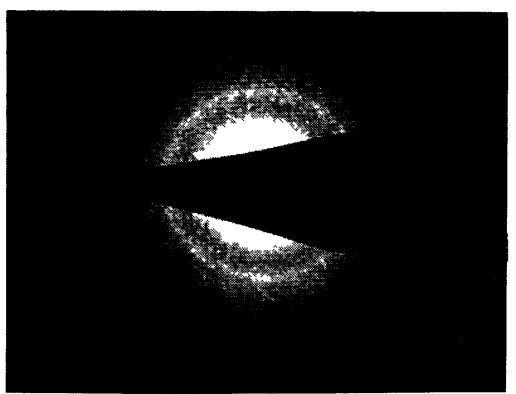

$$
t=10 s\left(\text { dose }=20 e / \AA^{2}\right)
$$

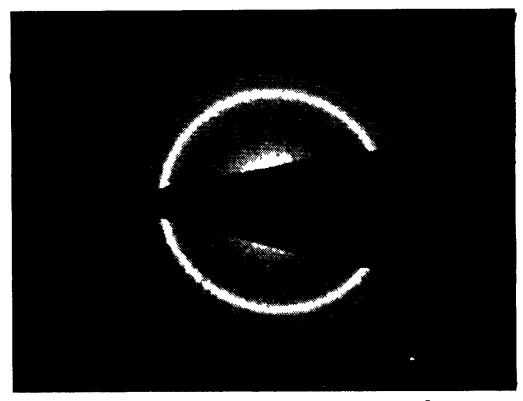

$$
\mathrm{t}=110 \mathrm{~s}\left(\operatorname{dose}=220 \mathrm{e} / \AA^{2}\right)
$$

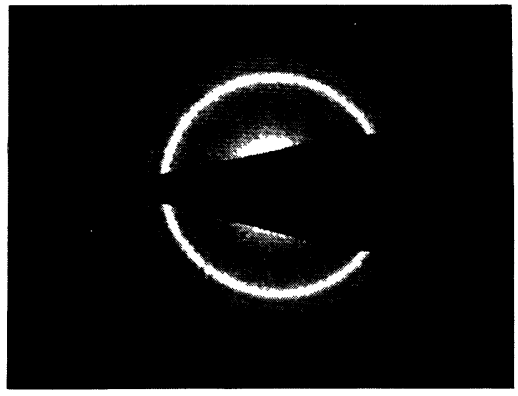

$$
\mathrm{t}=400 \mathrm{~s}\left(\text { dose }=800 \mathrm{e} / \AA^{2}\right)
$$

Fig. 2. - Evolution of low dose selected area electron diffraction patterns of lead isooctanoate particles as a function of irradiation time for a dose rate of $2 \mathrm{e} / \AA^{2} \mathrm{~s}$. 


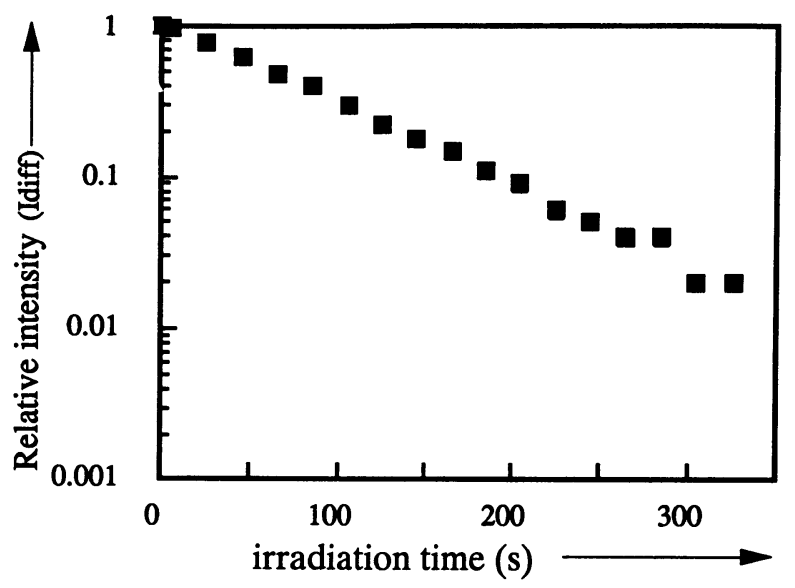

Fig. 3. - Variation of the logarithm of the relative intensity of the second Debye-Scherrer ring as function of irradiation time.

(ASTM $\mathrm{n}^{\circ}$ 4-0686) implying that, during the irradiation, the particles evolved from a low ordered organometallic structure into well organized f.c.c. lead lattice.

The variation of the logarithm of the relative intensity $I_{\text {diff }}$ of the second Debye-Scherrer ring as function of irradiation time is reported in figure 3. The linear curve obtained (negative slope of $\left.(-0.012 \pm 0.001) \mathrm{s}^{-1}\right)$ points out that the irradiation mechanism is a first order process (disappearance speed of micellar structure proportional to concentration of micelles) which will be discussed in the next section.

4.2 Molecular EVOLUTION. - As it is well established $[18,19]$, in the dipolar approximation (valid for small scattering angles typically in the range $10 \mathrm{mrad}$ for $200 \mathrm{kV}$ ), electron energy loss near edge structures of carbon K edge, are related to the bonding states of carbon (single or double bonds) in the molecular species; the energies of these transitions being affected by the so called chemical shift [20] depending on the electronegativity of the neighbours of the carbon.

Figure 4 presents near edge structures recorded on various carbonaceous standard compounds: graphite, amorphous carbon, lead carbonate, and lead isooctanoate. The attribution (according to previous works [18-22]) and the energy of the features are summarized in table I.

The evolution as a function of irradiation time of the near edge structures and corresponding second derivatives (for a dose rate of $2 \mathrm{e} / \AA^{2} \mathrm{~s}$ ) are presented in figure 5 for the lead isooctanoate particles. At the beginning $(t=4 \mathrm{~s})$ only the near edge structures characteristic of $1 \mathrm{~s} \rightarrow \sigma^{*}(\mathrm{C}-\mathrm{H})$, $1 \mathrm{~s} \rightarrow \sigma^{*}(\mathrm{C}-\mathrm{C}), 1 \mathrm{~s} \rightarrow \pi^{*}(\mathrm{C}=\mathrm{O})$ and $1 \mathrm{~s} \rightarrow \sigma^{*}(\mathrm{C}-\mathrm{C})$ transitions are visible (especially on the second derivative). During the irradiation process, the $1 \mathrm{~s} \rightarrow \sigma^{*}(\mathrm{C}-\mathrm{H})$ transition decreases and the typical 1s $\rightarrow \pi^{*}(\mathrm{C}=\mathrm{C})$ transition appears and increases as a function of time. Simultaneously we can note the weakening of the $1 \mathrm{~s} \rightarrow \pi^{*}(\mathrm{C}=\mathrm{O})$ signal. At the end of the examination $(t=106 \mathrm{~s})$, the carbon $\mathrm{K}$ edge is very similar to that of amorphous carbon. So it can be deduced that during the electron irradiation, hydrogen atoms and carboxylate groups are lost, leading to the creation of insaturations ( $\mathrm{C}=\mathrm{C}$ bonds).

In order to confirm the loss of oxygen species, time resolved quantitative analyses have been carried out on the specimen.

4.3 OXYGEN LOSS. - The evolution as a function of time of oxygen $\mathrm{K}$ edge intensity in the 


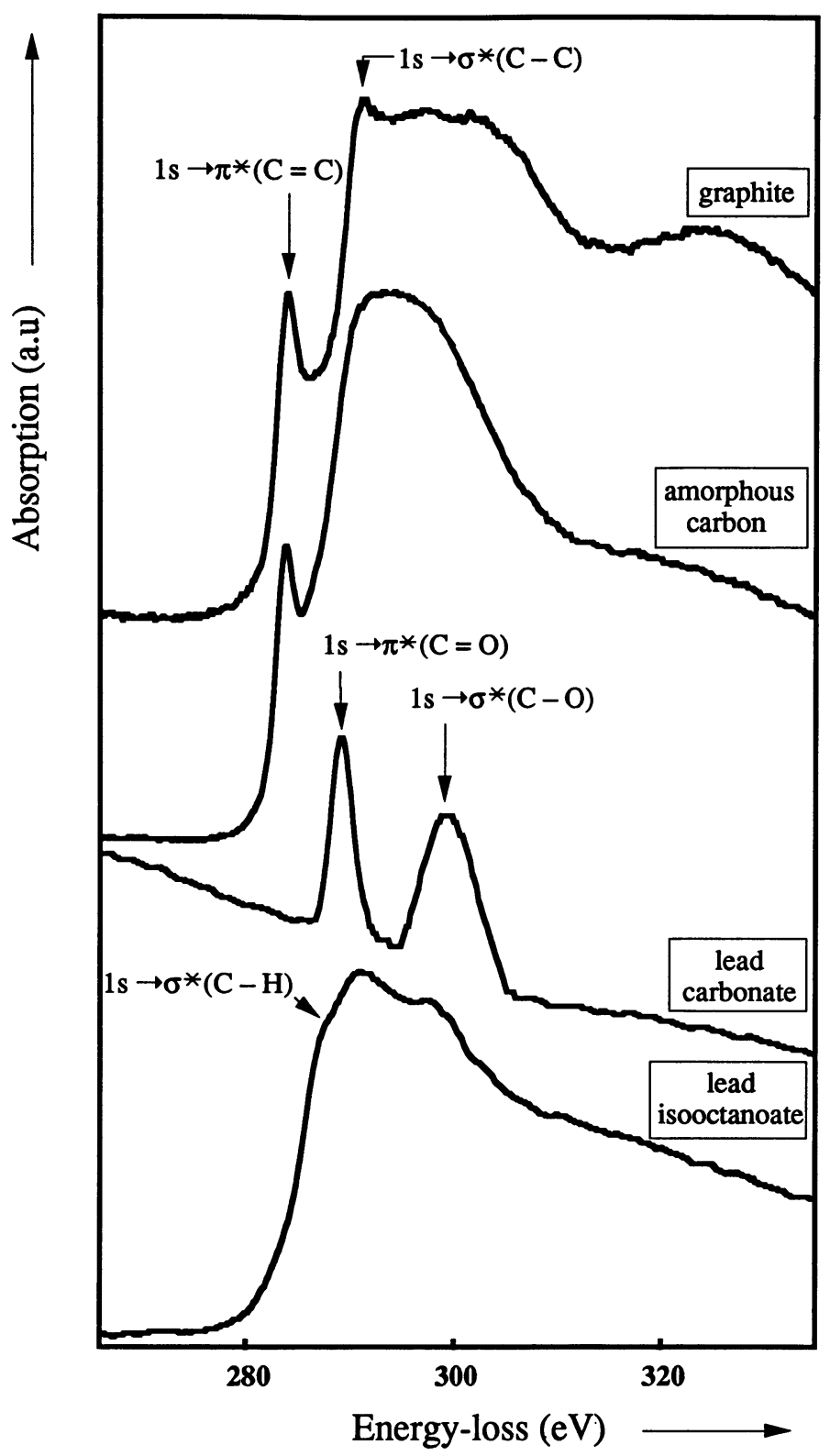

Fig. 4. - Near edge structures of carbon $\mathrm{K}$ edge recorded on various carbonaceous standard compounds and lead isooctanoate.

specimen for a constant dose rate of $240 \mathrm{e} / \AA^{2} \mathrm{~s}$ is presented in figure 6 . The quantitative results obtained using Gatan EL/P software are shown in figure 7. The background is fitted with a powerlaw function ( $A . E^{-r}$ where $E$ is the energy-loss, $A$ and $r$ are extrapolated constants [23]) and the integration window is $70 \mathrm{eV}$ wide.

The curve representing the logarithm of the oxygen concentration [O] as a function of the irradiation time shows that, during irradiation, the number of oxygen atoms decreases from $20010^{18}$ 
Table I. - Attribution and energy of near edge structures recorded on various carbonaceous standard compounds and lead isooctanoate.

\begin{tabular}{|c|c|c|}
\hline Electron transition & $\begin{array}{c}\text { Energy - loss } \\
(\mathrm{eV})\end{array}$ & Compound \\
\hline 1s $\rightarrow \pi^{*}(\mathrm{C}=\mathrm{C})$ & $\begin{array}{l}284 \\
284 \\
284\end{array}$ & $\begin{array}{c}\text { graphite } \\
\text { amorphous carbon } \\
\text { lead isooct. }\end{array}$ \\
\hline $1 \mathrm{~s} \rightarrow \sigma^{*}(\mathrm{C}-\mathrm{H})$ & 288 & lead isooct. \\
\hline $1 \mathrm{~s} \rightarrow \pi^{*}(\mathrm{C}=\mathrm{O})$ & $\begin{array}{c}289,5 \\
290\end{array}$ & $\begin{array}{c}\text { lead carbonate } \\
\text { lead isooct. }\end{array}$ \\
\hline $1 \mathrm{~s} \rightarrow \sigma^{*}(\mathrm{C}-\mathrm{C})$ & $\begin{array}{l}291 \\
291 \\
291\end{array}$ & $\begin{array}{c}\text { graphite } \\
\text { amorphous carbon } \\
\text { lead isooct. }\end{array}$ \\
\hline $1 \mathrm{~s} \rightarrow \sigma^{*}(\mathrm{C}-\mathrm{O})$ & $\begin{array}{c}299,5 \\
299\end{array}$ & $\begin{array}{l}\text { lead carbonate } \\
\text { lead isooct. }\end{array}$ \\
\hline
\end{tabular}

at.m $\mathrm{m}^{-2}$ down to a value of $7010^{18}$ at.m $\mathrm{m}^{-2}$ which seems to remain stable as a function of time. This loss of $65 \%$ of the oxygen atoms during the irradiation process confirms that both carboxylic groups and oxygen contained in the mineral core are lost.

The curve can be decomposed into two linear parts. The first one, with a negative slope of $(-0.026 \pm 0.003) \mathrm{s}^{-1}$ confirm the first order of the irradiation damage process as previously seen in diffraction. The second linear part (asymptotic part) can be attributed to remaining oxygen species at the surface of the specimen due to reaction of activated surface species with oxygen atoms present in the microscope vacuum.

4.4 INFLUENCE OF THE DOSE RATE. - In order to study the influence of the dose rate on the irradiation damage processes we studied the dose needed to create a given irradiation damage concentration [ID] as a function of the dose rate. These experiments have been carried out by means of electron diffraction. [ID] is determined by the appearance of the third Debye-Scherrer ring (characteristic of f.c.c. lead) in the diffraction patterns.

The results are presented in figure 8 in lin/Log coordinates. The curve presents two distinct parts. The first one in the range $0.1-10 \mathrm{e} / \AA^{2} \mathrm{~s}$ is linear and parallel to the $\mathrm{J}$ axis. It points out the fact that the total dose responsible of the irradiation damage concentration [ID] is independant on the dose rate. In other terms, the irradiation damage amount only depends on the total dose, which is in agreement with the single hit theory [24]. On the contrary for high dose rates $(10<$ $\left.J<1000 \mathrm{e} / \AA^{2} \mathrm{~s}\right)$, the curve increases and points out that the admissible total dose, for the given irradiation damage concentration [ID], increases as a function of the dose rate. It demonstrates that, in this region, the irradiation damage concentration do not remains proportional to the total dose and consequently that the one hit theory is no longer valid.

\section{Discussion and interpretation.}

The quantitative results obtained at the level of diffraction and electron energy loss experiments allow us to conclude that in our conditions the irradiation damage reaction is a first order process. This conclusion being strongly supported by the linearity of the curves $\log I_{\text {diff }}$ and $\log [\mathrm{O}]$ as a 

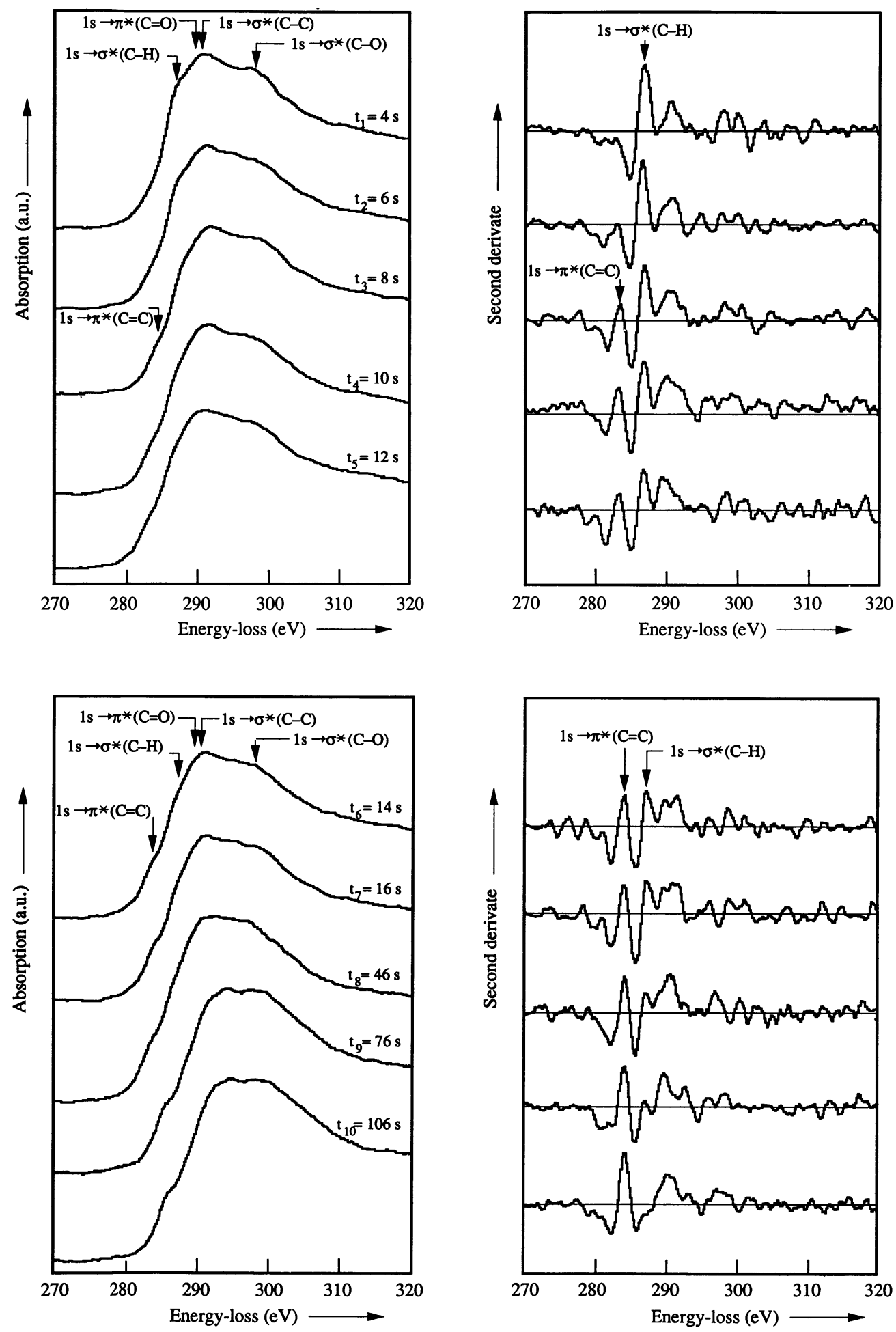

Fig. 5. - Evolution of the carbon $\mathrm{K}$ near edge structures and corresponding second derivatives as a function of irradiation time for the lead isooctanoate particles (dose rate $=2 \mathrm{e} / \AA^{2} \mathrm{~s}$ ). 


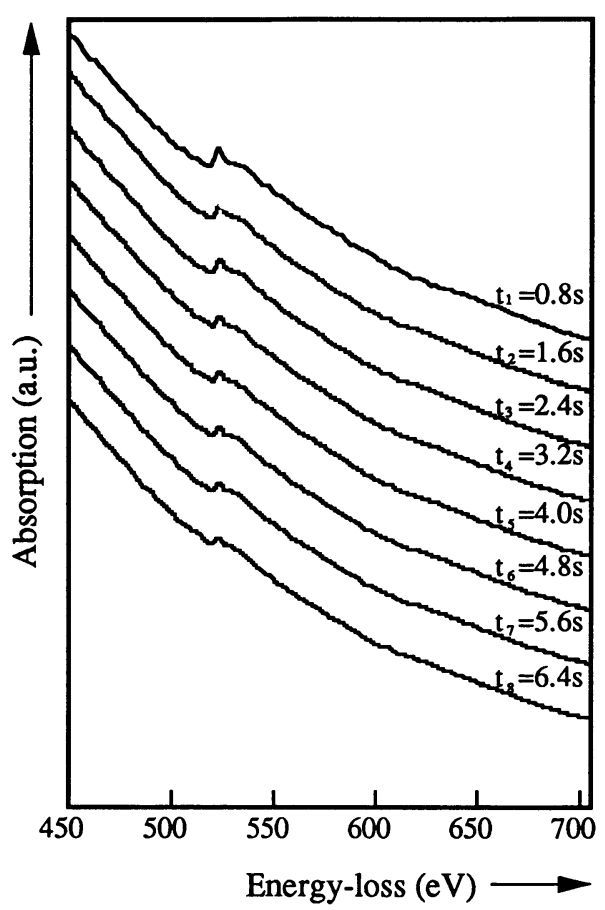

Fig. 6. - Variation of the oxygen $\mathrm{K}$ edge intensity for the lead isooctanoate particles as a function of irradiation time (dose rate $=240 \mathrm{e} / \AA^{2} \mathrm{~s}$ ) in $\mathrm{Log} /$ lin coordinates.

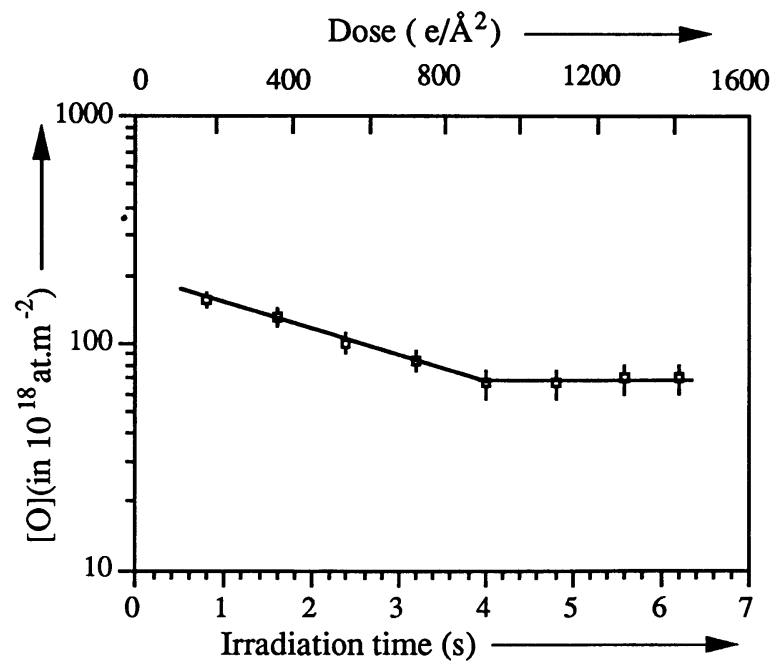

Fig. 7. - Evolution of the oxygen concentration as a function of irradiation time in Log/lin coordinates. 


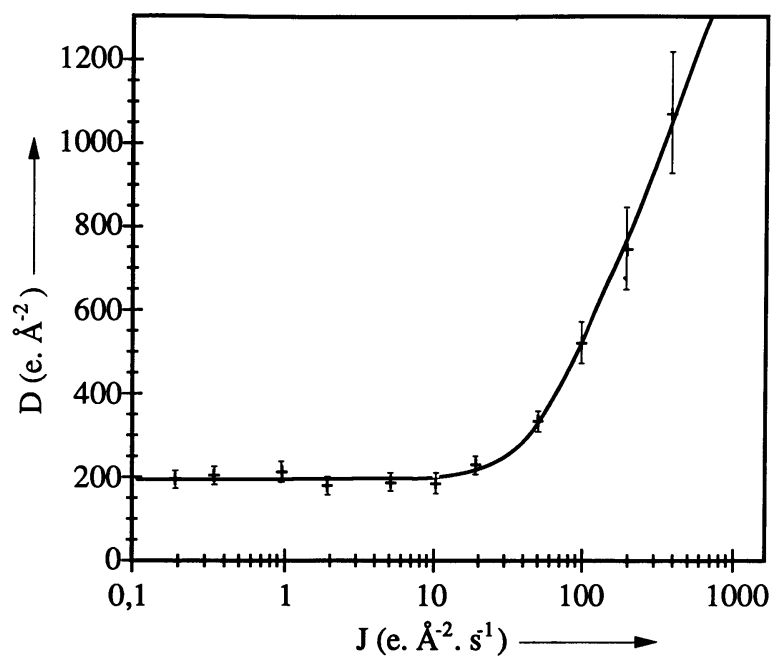

Fig. 8. - Variation of irradiation dose as a function of electron dose rate for a constant irradiation damage concentration in $\log / \mathrm{Log}$ coordinates.

function of irradiation time. The negative slopes being $(-0.012 \pm 0.001) \mathrm{s}^{-1}$ and $(-0.26 \pm 0.03)$ $\mathrm{s}^{-1}$ for diffraction and EELS results respectively.

In a first approximation the irradiation damage process can be roughly described as a chemical reaction summarized as:

$$
\mathrm{PbIso}+\mathrm{e}^{-} \longrightarrow \text { degradation products }
$$

In that hypothesis the kinetic equation relative to the disappearance of lead isooctanoate can be written as:

$$
\frac{\mathrm{d}}{\mathrm{d} t}[\mathrm{PbIso}]=-k_{\beta}[\mathrm{PbIso}]^{\alpha} \bullet\left[\mathrm{e}^{-}\right]^{\beta}
$$

The electrons being considered as reactive species. The "concentration" of these ones $\left[\mathrm{e}^{-}\right]$is in fact the electron dose rate $J$. The exponents $\alpha$ and $\beta$ represent the partial order of the reaction relative to the lead isooctanoate concentration and electron dose rate respectively. The speed constant $k_{\beta}$ is expressed in $(\mathrm{Mol})^{1-\alpha}\left(\mathrm{e}^{-2} \mathrm{~s}^{-1}\right)^{-\beta} \mathrm{s}^{-1}$.

In our case, the dose rate remains constant during the irradiation experiment and consequently can be included into the reaction speed constant $K=k_{\beta} \cdot\left[\mathrm{e}^{-}\right]^{\beta}=k_{\beta} . J^{\beta}$.

The kinetic equation (1) can be written as:

$$
\frac{\mathrm{d}}{\mathrm{d} t}[\mathrm{PbIso}]=-K[\mathrm{PbIso}]^{\alpha}
$$

The linearity of experimental curves, $\log I_{\text {diff }}$ and $\log [\mathrm{O}]$ as a function of irradiation time (Figs. 3 and 7) lead to $\alpha=1$. Consequently the solution of the preceeding differential equation has the following form:

$$
[\mathrm{PbIso}]_{\mathrm{t}}=[\mathrm{PbIso}]_{0} \mathrm{e}^{-K . t}
$$

with $K=k_{\beta} . J^{\beta}$.

In order to deduce and compare the $k_{\beta}$ values for each type of experiment (electron diffraction and EELS) the partial order $\beta$, relative to $J$, is needed because the two experiments have been 
carried out with strongly different electron dose rate $\left(2 \mathrm{e} / \AA^{2} . s\right.$ for diffraction and $240 \mathrm{e} / \AA^{2} . s$ for EELS).

Using the expression (2) for a fixed dose rate $J$ we can express the time $t_{\mathrm{D}}$ needed to produce an irradiation damage concentration [ID] (corresponding to a final lead isooctanoate concentration [PbIso $\left.]_{D}\right)$ :

$$
t_{\mathrm{D}}=\frac{1}{K} \log \frac{[\mathrm{PbIso}]_{0}}{[\mathrm{PbIso}]_{\mathrm{D}}}=\frac{1}{k_{\beta} J^{\beta}} \log \frac{[\mathrm{PbIso}]_{0}}{[\mathrm{PbIso}]_{\mathrm{D}}}
$$

The irradiation dose $D$ needed to produce [ID] is then:

$$
D=J . t_{\mathrm{D}}=\frac{J^{(1-\beta)}}{k_{\beta}} \log \frac{[\mathrm{PbIso}]_{0}}{[\mathrm{PbIso}]_{\mathrm{D}}}
$$

Using the experimental data (Fig. 8) the constant term $\frac{1}{k_{\beta}} \log \frac{[\mathrm{PbIso}]_{0}}{[\mathrm{PbIsO}]_{\mathrm{D}}}$ can be deduced from the part where the single hit theory is valid. In this case $\beta=1$ and the asymptotic value $D_{\mathrm{A}}$ is equal to:

$$
D_{\mathrm{A}}=\frac{1}{k_{\beta=1}} \log \frac{[\mathrm{PbIso}]_{0}}{[\mathrm{PbIso}]_{\mathrm{D}}}=200 \mathrm{e} / \AA^{2}
$$

so $D$ can be written as:

$$
D=\frac{k_{\beta=1}}{k_{\beta}} J^{1-\beta} D_{\mathrm{A}}
$$

which leads to:

$$
\frac{D}{D_{\mathrm{A}}}=\frac{k_{\beta=1}}{k_{\beta}} J^{1-\beta} \quad \text { with } \frac{k_{\beta=1}}{k_{\beta}}=1\left(\mathrm{e}^{-2} \mathrm{~s}^{-1}\right)^{\beta-1}
$$

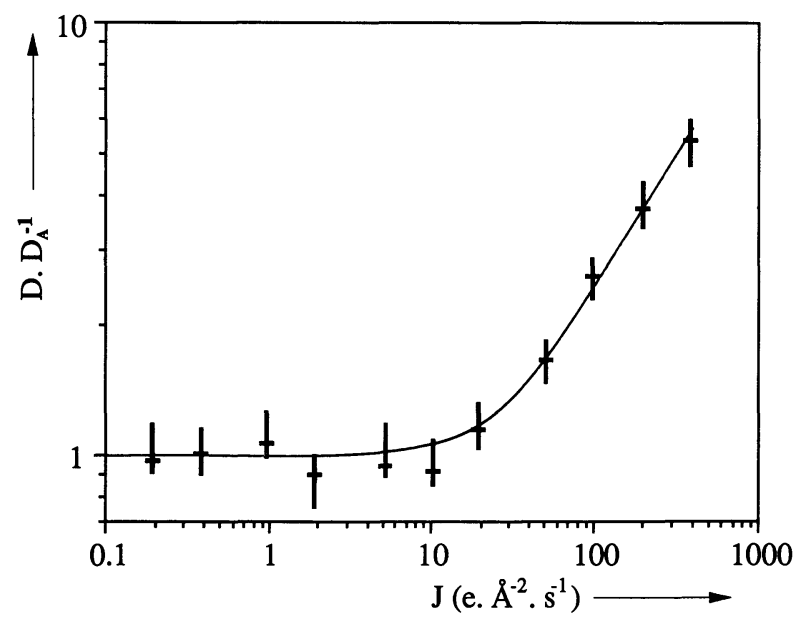

Fig. 9. - Evolution of $D \cdot D_{\mathrm{A}}^{-1}$ as a function of dose rate for constant irradiation damage concentration in Log/Log coordinates. 


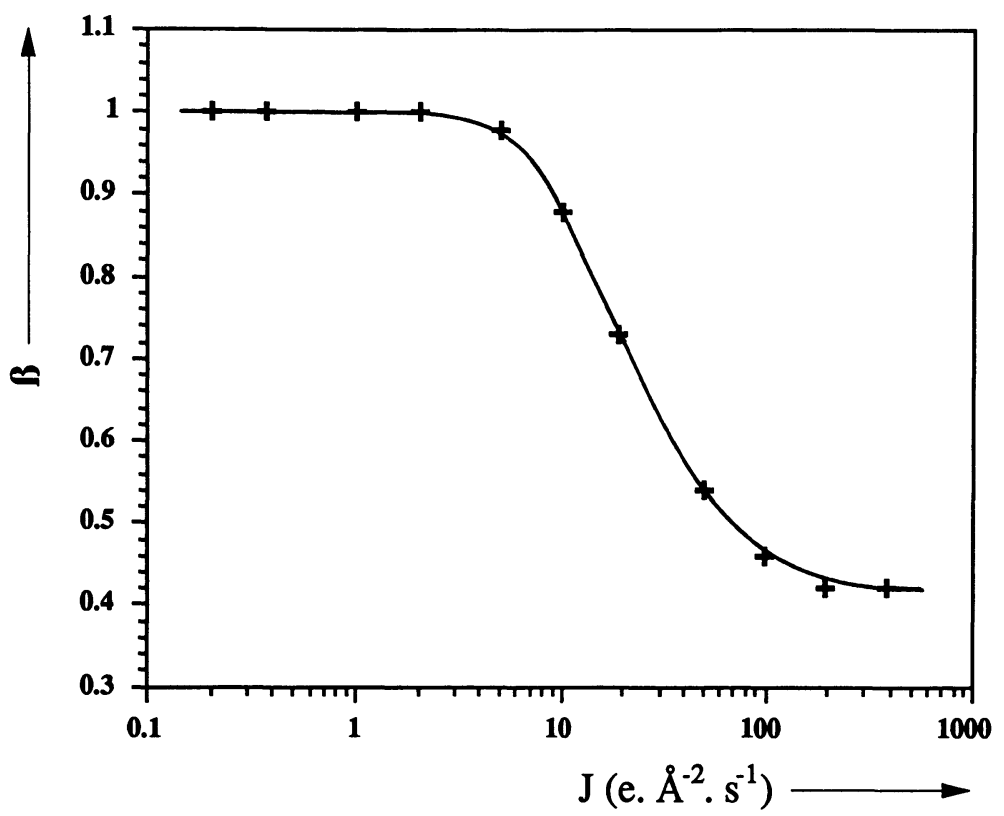

Fig. 10. - Variation of the $\beta$ exponent as a function of dose rate in lin/Log coordinates.

The evolution of $\log \left(D \cdot D_{\mathrm{A}}^{-1}\right)$ as a function of $J$ (Fig. 9) for constant irradiation damage concentration allows us to deduce the exponent $\beta$ for each value of the experimental dose rate.

The curve representing $\beta$ as a function of $J$ is presented in figure 10 . As previously mentioned, in the low dose rate range ( $\left.<10 \mathrm{e} / \AA^{2} \mathrm{~s}\right), \beta$ is equal to one. For higher values $\beta$ decreases down to an asymptotic value of $0.4 \pm 0.05$.

This decrease of $\beta$ (partial order lower than one) simply shows a loss of efficiency of the electron matter interactions to produce irradiation damage at high dose rate (one electron produces the bond breakage and other ones interact with the created free species during its diffusion in the sample). The fact that $\beta$ tends to an asymptotic value is not surprising but the value obtained can be overestimated due to the thermal effects which become important at high electron dose rates.

Introducing the values of $\beta$ for the electron dose rate used for diffraction and EELS experiments the corresponding $k$ values can be deduced.

For electron diffraction:

$$
k=\frac{0.012}{2}=0.006 \pm 0.001 \mathrm{~s}^{-1}
$$

For EELS:

$$
k=\frac{0.26}{(240)^{0.42}}=0.025 \pm 0.010 \mathrm{~s}^{-1}
$$

The two found $k$ values are of the same order. However the $k$ value in the case of EELS is a greater (with respect to absolute error) than in diffraction experiment. This could be attributed 
to the following points:

The samples for diffraction and EELS studies where prepared with two different methods leading to slighty different thicknesses (this parameter is not taken into account in this simple model).

In the case of diffraction the colloidal particles are deposited onto a carbon film whereas for EELS studies the "Langmuir film" is hanging in the holes of a holey carbon layer. In a first approximation the behaviour of the two specimens will be different especially at the level of thermal exchanges (and consequently thermal equilibrium under irradiation).

The irradiation damage studied by Electron Diffraction are concerned with the organization changes of the mineral part of the particles whereas the EELS study allows us to investigate the chemical changes (loss of oxygen) in the whole material (mineral and organic parts).

\section{Conclusion.}

The experimental studies of irradiation damage carried out on lead isooctanoate by means of electron energy loss spectroscopy and electron diffraction allowed us to point out the influence of dose rate onto the admissible total dose producing a given amount of irradiation damage. We especially demonstrated that for low dose rate (lower than $10 \mathrm{e} / \AA^{2} \mathrm{~s}$ ) the single hit theory is valid and the irradiation damage amount is proportional to the dose. For high dose rates the single hit theory is no longer valid. The experimental results underline that the electron dose needed to produce a constant irradiation damage concentration increases as a function of the dose rate used. A quantitative kinetic approach points out that the irradiation damage process is a first order one relative to the lead isooctanoate concentration. The partial order relative to the electron dose rate decreases from one in the dose rate range $0.1<J<10 \mathrm{e} / \AA^{2} \mathrm{~s}$ down to 0.4 for high dose rates $\left(J>100 \mathrm{e} / \AA^{2} \mathrm{~s}\right)$.

On a chemical point view the study of the evolution as a function of the irradiation time of the near edge structures of the carbon $\mathrm{K}$ edge and oxygen concentration in the specimen allows us to conclude that in the degradation process, losses of carboxylic species and hydrogen atoms lead to the creation of unsaturated bonds $(C=C)$. The final state of the organic shell being close to amorphous carbon. The mineral core evolution followed by low dose electron diffraction points out the loss of oxygen with reorganisation of the mineral core into pure f.c.c. metallic lead.

\section{References}

[1] Youngman R.A., HobBs L.W. and Michell T.E., J. Phys. France 41 (1980) C6-227.

[2] Mochel M.E., HumphreYs C.J., EAdes J.A., Mochel J.M. and PeTFORd A.M., Appl. Phys. Lett. 45 (4) (1983) 392.

[3] BuCKETT M.I., STRANe J., LuZZI D.E., ZhANG J.P., Wessels B.W. and MARKS L.D., Ultramicroscopy 29 (1989) 217-227.

[4] DeVENISH R.H., Bullough T.J., TuRNER P.S. and HuMPHREYS C.J., Emag-Micro 89 London (1989) p. 215.

[5] EGERTON R.F., J. Microsc. 118 (8) (1980) 389-399.

[6] MurRay A., ISAACSON M. and ADÉsidA I., Appl. Phys. Lett. 45 (5) (1984) 589.

[7] HoBBS L.W., Radiation effects in analysis by TEM in Quantitative Electron Microscopy, Ed Chapman and Craven (1984) p. 399.

[8] GrubBS D.T. and Groves G.W., Philos. Mag. 24 (1971) 815.

[9] GLAESER R.M., Radiation Damage and Biological Electron Microscopy in Physical Aspects of Electron microscopy and Microbeam Analysis, chap. 12 (J. Wiley, N.Y., 1975). 
[10] IsAACsON M., Specimen Damage in the Electron Microscope in Principles and Techniques of Electron Microscopy, chap. 1 (van Nostrand-Reinhold, N.Y., 1977).

[11] ReIMER L., Transmission Electron Microscopy, Springer series in Optical Sciences 36 (SpringerVerlag, N.Y., 1984).

[12] WERY J., Thesis (Nantes Univ. 1992).

[13] STEPHENS J.F. and TUCK-LEE C., J. Appl. Cryst. 2 (1969) 1.

[14] MANSOT J.L., LAGARDE P., First ECIS Congress (Como, 1987).

[15] MANSOT J.L., HALlOUIS M., MARTIN J.M., Coll and Surf, in press (1993).

[16] KRIVANEK O.L., AHN C.C. and KeENEY R.B., Ultramicroscopy 22 (1987) 103.

[17] COSSLETT V.E., J. Microsc. 113 (P2) (1978) 113-129.

[18] Comelli G., STÖHR J., Robinson C.J. and JARK W., Phys. Rev. B 38 (1988) 7511.

[19] RITSKo J.J., J. Chem. Phys. 70 (1979) 12.

[20] LeAPMAN R.D., Grunes L.A. et Fejes P.L., Phys. Rev. B 26 (1985) 614.

[21] STÖHR J., "NEXAFS Spectroscopy", 162-210, R. Gomer (Springer-Verlag, N.Y., 1992).

[22] ADE H., ZhANG X., CAMERON S., COSTEllo C., KIRZ J. and Williams S., Science 258 (1992) 972-975.

[23] EGERTON R.F., Ultramicroscopy 3 (1978) 243-251.

[24] JUNG H. and DERTINGER H., in "Molecular Radiation Biology”, 12-23 (Springer-Verlag, Berlin, 1970).

Commission paritaire $\mathrm{N}^{\circ}$ en cours 